\title{
BMJ Open Characteristics, complications and outcomes among 1549 patients hospitalised with COVID-19 in a secondary hospital in Madrid, Spain: a retrospective case series study
}

\author{
Eva Jiménez (D) , ${ }^{1}$ Mario Fontán-Vela, ${ }^{1}$ Jorge Valencia, ${ }^{2}$ Ines Fernandez-Jimenez, ${ }^{1}$ \\ Elena Alba Álvaro-Alonso, ${ }^{3}$ Elsa Izquierdo-García, ${ }^{3}$ Andrea Lazaro Cebas, ${ }^{3}$ \\ Elisa Gallego Ruiz-Elvira, ${ }^{1}$ Jesús Troya, ${ }^{2}$ Ana Josefa Tebar-Martinez, ${ }^{1}$ \\ Belén Garcia-Marina, ${ }^{4}$ Gabriela Peña-Lillo, ${ }^{4}$ Ane Abad-Motos, ${ }^{5}$ Laura Macaya, ${ }^{6}$ \\ Pablo Ryan, ${ }^{2}$ Mario Pérez-Butragueño (D) ,7 COVID@HUIL Working Group, On \\ behalf of the COVID@HUIL Working Group
}

To cite: Jiménez E, FontánVela M, Valencia J, et al. Characteristics, complications and outcomes among 1549 patients hospitalised with COVID-19 in a secondary hospital in Madrid, Spain: a retrospective case series study. BMJ Open 2020;10:e042398. doi:10.1136/ bmjopen-2020-042398

- Prepublication history and additional material for this paper are available online. To view these files, please visit the journal online (http://dx.doi. org/10.1136/bmjopen-2020042398).

MF-V and PR contributed equally.

Received 03 July 2020 Revised 20 0ctober 2020 Accepted 23 0ctober 2020

\section{Check for updates}

(c) Author(s) (or their employer(s)) 2020. Re-use permitted under CC BY-NC. No commercial re-use. See rights and permissions. Published by BMJ.

For numbered affiliations see end of article.

Correspondence to Dr Eva Jiménez; ejgonzalezbuitrago@salud. madrid.org

\section{ABSTRACT}

Objectives To describe demographic, clinical, radiological and laboratory characteristics, as well as outcomes, of patients admitted for COVID-19 in a secondary hospital.

Design and setting Retrospective case series of sequentially hospitalised patients with confirmed SARSCoV-2, at Infanta Leonor University Hospital (ILUH) in Madrid, Spain.

Participants All patients attended at ILUH testing positive to reverse transcriptase-PCR on nasopharyngeal swabs and diagnosed with COVID-19 between 1 March 2020 and 28 May 2020.

Results A total of 1549 COVID-19 cases were included (median age 69 years (IQR 55.0-81.0), 57.5\% men). $78.2 \%$ had at least one underlying comorbidity, the most frequent was hypertension (55.8\%). Most frequent symptoms at presentation were fever $(75.3 \%)$, cough $(65.7 \%)$ and dyspnoea (58.1\%). 81 (5.8\%) patients were admitted to the intensive care unit (ICU) (median age 62 years (IQR 51-71); 74.1\% men; median length of stay 9 days (IQR 5-19)) $82.7 \%$ of them needed invasive ventilation support. 1393 patients had an outcome at the end of the study period (case fatality ratio: $21.2 \%$ (296/1393)). The independent factors associated with fatality $(0 \mathrm{R} ; 95 \% \mathrm{Cl})$ : age $(1.07 ; 1.06$ to 1.09$)$, male sex (2.86; 1.85 to 4.50$)$, neurological disease $(1.93 ; 1.19$ to 3.13$)$, chronic kidney disease (2.83; 1.40 to 5.71 ) and neoplasia (4.29; 2.40 to 7.67$)$. The percentage of hospital beds occupied with COVID-19 almost doubled (702/361), with the number of patients in ICU quadrupling its capacity (32/8). Median length of stay was 9 days (IQR 6-14).

Conclusions This study provides clinical characteristics, complications and outcomes of patients with COVID-19 admitted to a European secondary hospital. Fatal outcomes were similar to those reported by hospitals with a higher level of complexity.
Strengths and limitations of this study

This is a large retrospective case series study of 1549 sequentially hospitalised patients with confirmed SARS-CoV-2.

- The study describes the response of a secondary hospital based in a region of Spain with the highest incidence of COVID-19, and how the hospital was transformed into a centre entirely dedicated to COVID-19.

- A complete follow-up was made of all patients during hospital stay, although after discharge no outcome information was collected, so only inhospital fatality could be estimated.

\section{BACKGROUND}

In December 2019, a novel coronavirus (SARS-CoV-2) emerged in China and spread globally, causing a new infectious disease named 'COVID-19'. 'By 28 May 2020, the epidemic reaches 5593631 confirmed cases and more than 353334 deaths across 216 countries all over the world. ${ }^{2}$

The first confirmed case of COVID-19 in Spain was reported from La Gomera (Canary Islands) on 31 January $2020 .^{3}$ But it was not until the last week of February 2020 when the first five cases were reported in the community of Madrid. ${ }^{4}$

During March and April 2020 (first COVID-19 wave in Spain and Europe), Spain had been one of the most affected countries by the coronavirus, being one of the main outbreaks of the disease worldwide. Spain is now the second country in Europe with the highest number of confirmed cases (after the 
Russian Federation) with 470973 cases as of 1 September $2020 .^{256}$ The rate of infections in the community of Madrid has exceeded every other region in Spain, with more than $27 \%$ of all confirmed cases in Spain and an accumulated number of 45074 hospitalised patients and 8662 deaths as of 1 September $2020 .^{5}$

Hospitals of the various regional health services of Spain are categorised into different complexity levels depending on their size, technological resources and the higher or lower availability of different clinical departments, thus, in ascending order of complexity we have primary, secondary and tertiary level hospitals; tertiary hospitals often have specific clinical departments that attend patients coming from different parts of the country. The Infanta Leonor University Hospital (ILUH) is a secondary level hospital with 361 beds, including 8 in the intensive care unit (ICU). It serves the population of Vallecas (305 262 individuals). ${ }^{7}$ Our healthcare area has a disproportionate number of beds per inhabitants: 1.07 beds per 1000 people compared with 2.15 beds per 1000 people overall within the region. Vallecas is one of the COVID-19 most affected areas in the city of Madrid (Spain) with 9947 total confirmed COVID-19 cases as of 1 September $2020 .{ }^{8}$ Therefore, the level of hospital saturation during the epidemy has been one of the greatest in Spain. As a consequence, the hospital was in March transformed into a centre entirely dedicated to COVID-19 and all its professionals focused on assisting patients affected by the SARS-CoV-2 infection.

Limited information is available to describe characteristics, complications and mortality in COVID-19 overloaded secondary Spanish hospitals. The available data from Spain refer to tertiary hospitals, multicentric studies or primary care settings. ${ }^{9-12}$

This study describes the clinical characteristics, severity, types of treatments and overall outcomes of patients with confirmed SARS-CoV-2 infection admitted to ILUH in Madrid (Spain).

\section{METHODS}

\section{Study design and participants}

A single-centre retrospective observational study that included patients attended at ILUH with a laboratoryconfirmed COVID-19 between 1 March 2020 and 28 May 2020. SARS-CoV-2 infection was confirmed by realtime reverse transcriptase-PCR (RT-PCR) assay (FTD SARS-CoV-2 Assay by SIEMENS) from nasopharyngeal swabs (Deltaswab by Deltalab). Patients discharged from the emergency department and those transferred to another hospital in the first 48 hours were not included in the final analysis; although these patients were hospitalised at ILUH, they did not stay enough time to record all the relevant clinical data due to the hospital overcapacity context. Once selected patients that met inclusion criteria, no one was excluded.

Epidemiological and demographic data, medical history, baseline comorbidities, symptoms and signs both at admission and during follow-up, laboratory findings, RT-PCR results, treatment strategy used for COVID-19, complications and survival data were obtained from patient's electronic medical records. All-cause mortality was calculated including deaths occurred both in patients pending admission (first 48 hours) and during hospitalisation. ICU admission, hospitalisation, length of stay and ventilatory support (invasive mechanical ventilation, noninvasive mechanical ventilation or oxygen mask) were also registered. Different time intervals were calculated: lag time between symptoms onset and diagnosis, length of stay at ICU and overall length of stay at the hospital.

Data were collected and managed using REDCap (Research Electronic Data Capture) electronic data capture tools hosted at Ideas for Health Association. REDCap is a secure, web-based software platform designed to support data capture for research studies. ${ }^{13}$

The Strengthening the Reporting of Observational Studies in Epidemiology statement guidelines were followed in the conduct and reporting of the study (see online supplemental file).

\section{Patient and public involvement}

There was no patient or public involvement in the development of the research design or in conducting the study.

\section{Statistical analysis}

A descriptive analysis of the clinical background and baseline characteristics of the patients was performed. Continuous variables are presented as median and IQR, after testing normal distribution. Categorical variables are expressed as number of patients and percentage. Two age groups were defined using a cut-off value of 65 ( $<65$ and $\geq 65$ years old) for the comparison of the clinical characteristics of the cohort. For the ICU analysis, the comparison of the characteristics between admitted and non-admitted to ICU patients was limited to patients under 65 years because age was one of the major criteria for a better allocation of ICU resources in a context of limited availability of them.

For the mortality analysis, the case fatality ratio (CFR) was defined as number of deaths of patients with laboratory-confirmed COVID-19 divided by the number of laboratory-confirmed COVID-19 cases admitted to the hospital. The outcomes were defined as death or recovered, and the clinical characteristics between these groups were compared using $\mathrm{X}^{2}$ test for the categorical variables and median test for the quantitative variables.

Logistic regression analysis was carried out to ascertain the effect of sociodemographic and clinical background characteristics on mortality. Variables that showed statistical significance $(\mathrm{p}<0.05)$ in the univariate analysis and clinical variables that could have potential relevance on the outcome according to the current available evidence were included in the model. OR and 95\% CIs were calculated.

Statistical analyses were done using Stata software (V.14.0; Stata Corporation, College Station, Texas, USA). 


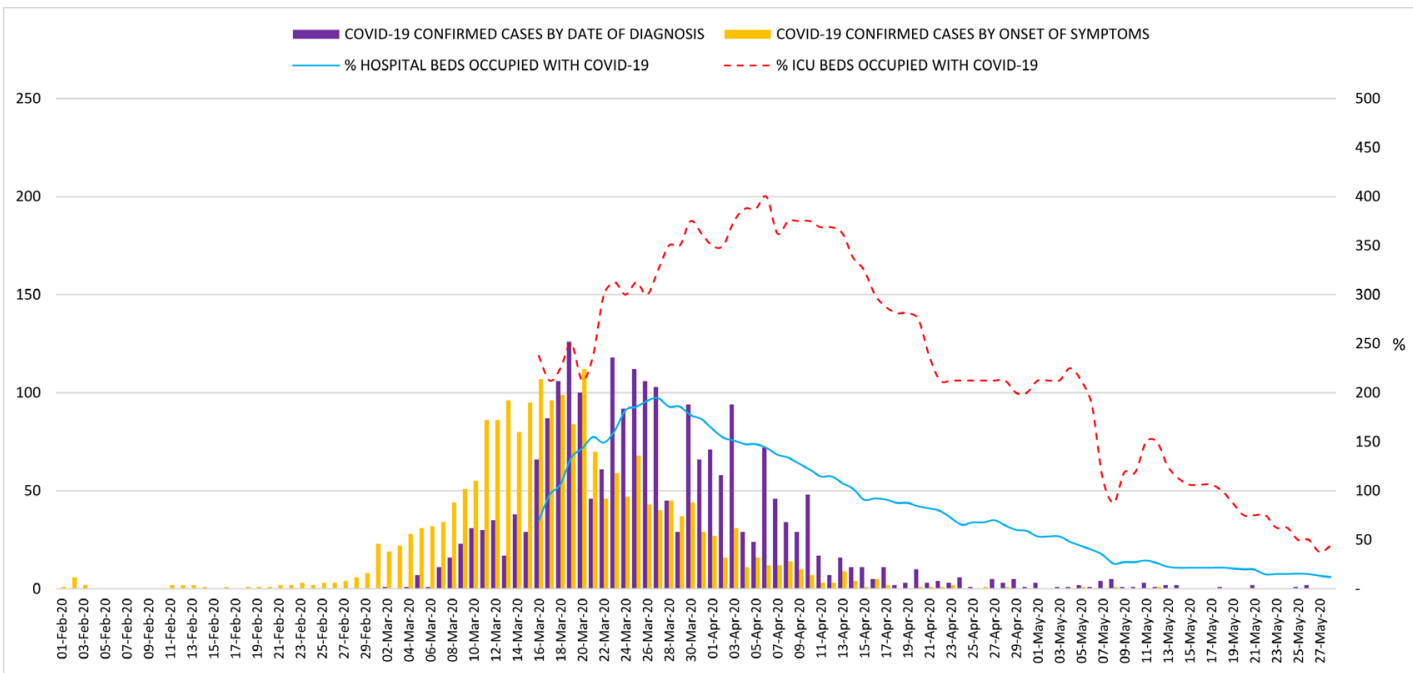

Figure 1 Epidemic curve of COVID-19 confirmed cases seen at ILUH. ILUH, Infanta Leonor University Hospital.

\section{RESULTS}

Overall, 2259 COVID-19 confirmed cases were attended at ILUH during the study period. The daily number of confirmed COVID-19 cases are plotted by the date of diagnosis (date of positive RT-PCR) and by the date of symptoms onset in figure 1 . The first positive patient in our hospital was diagnosed on 1 March 2020 and the epidemic curve peaked on 19 March when 126 PCR tested positive. From that date, the incidence declined gradually but it took over a month to have a daily number of new cases below 10. The percentage of ICU beds and total hospital beds occupied with patients with COVID-19 are shown in figure 1. On $27 \mathrm{March}$, our hospital almost doubled its bed capacity with 702 hospitalised patients.
On 6 April, 32 patients were in ICU, reaching $400 \%$ of hospital ICU capacity.

Among these 2259 patients, we analysed 1549 cases and excluded 710 because they were discharged from the emergency department or transferred to other hospitals in the first 48 hours. For the complications, ICU and mortality analysis, 156 patients with an incomplete episode were excluded because they were transferred to other hospitals during their stay or were still hospitalised by 28 May 2020 (figure 2 ).

Age range of the 1549 hospitalised patients varied from 3 weeks to 102 years old, median was 69 (IQR 55.0-81.0), and $57.5 \%$ were men. All patients except for the 3-week-old baby were adults. Of these, $55.0 \%$

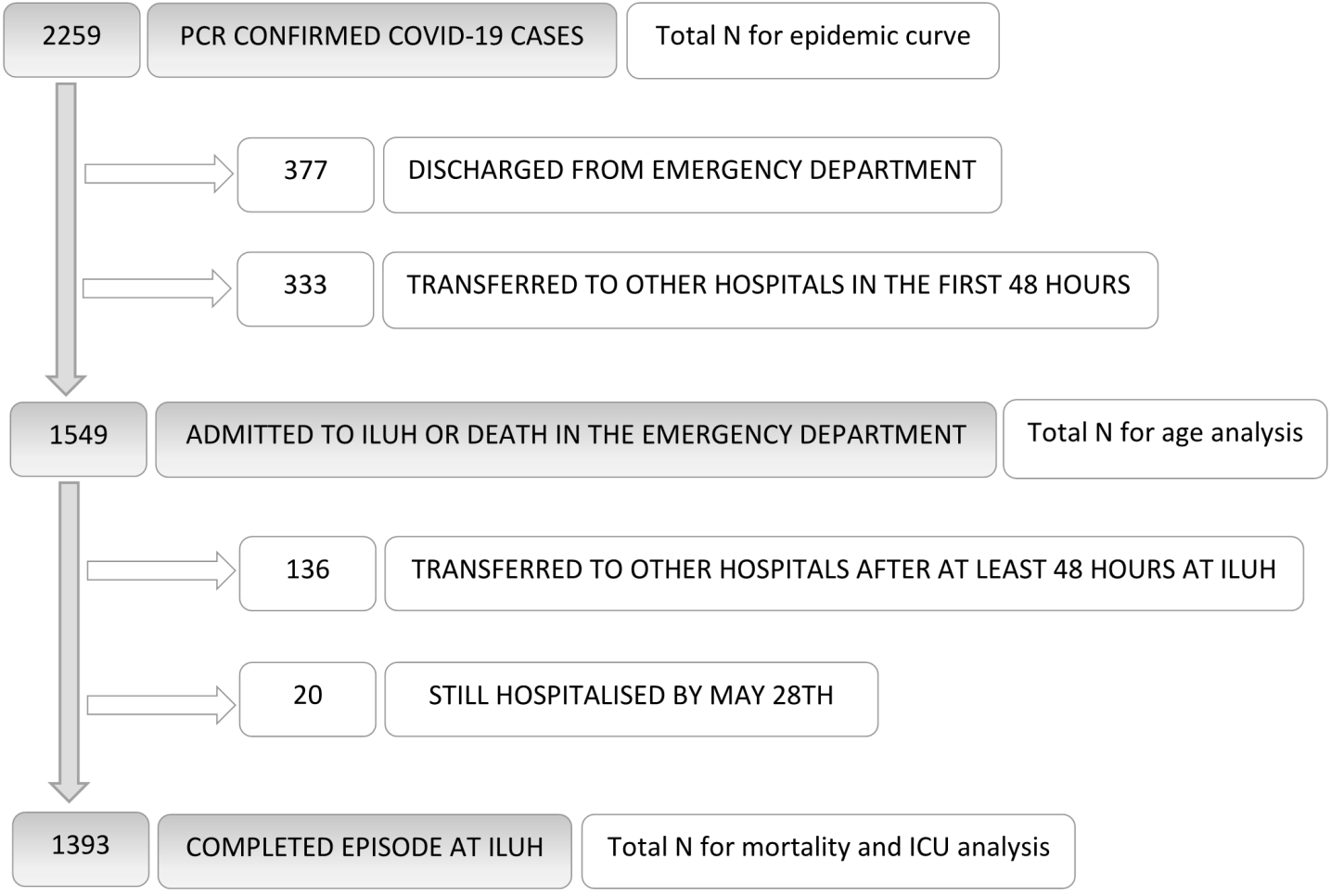

Figure 2 Population flow chart. ICU, intensive care unit; ILUH, Infanta Leonor University Hospital. 
Table 1 Clinical characteristics and treatment $(\mathrm{N}=1549)$

\begin{tabular}{|c|c|c|c|c|}
\hline & Overall & $<65$ years old & $\geq 65$ years old & \\
\hline & $\mathrm{n} / \mathrm{N}(\%)$ & $\mathrm{n} / \mathrm{N}(\%)$ & $\mathrm{n} / \mathrm{N}(\%)$ & $P$ value \\
\hline Male & $890 / 1549(57.5)$ & $400 / 642(62.3)$ & 490/907 (54.0) & 0.001 \\
\hline Clinical background & & & & \\
\hline Influenza vaccine 19/20 & 498/1101 (45.2) & 90/463 (19.4) & $408 / 638(63.9)$ & $<0.001$ \\
\hline Cardiological disease & $375 / 1545$ (24.3) & $37 / 640(5.8)$ & 338/905 (37.3) & $<0.001$ \\
\hline Diabetes mellitus & $382 / 1541(24.8)$ & $85 / 636(13.4)$ & 297/905 (32.8) & $<0.001$ \\
\hline Tobacco smoker/ex-smoker & $374 / 1344(27.8)$ & $121 / 555(21.8)$ & 253/789 (32.0) & $<0.001$ \\
\hline Obesity & $240 / 1531(15.7)$ & $110 / 636(17.3)$ & $130 / 895(14.5)$ & 0.129 \\
\hline COPD & $211 / 1541(13.7)$ & $37 / 638(5.8)$ & 174/903 (19.3) & $<0.001$ \\
\hline Asthma & $122 / 1545(7.9)$ & $51 / 639(8.0)$ & $71 / 906(7.8)$ & 0.668 \\
\hline Neurological disease & $178 / 1540(11.6)$ & $37 / 637(5.8)$ & $141 / 903(15.6)$ & $<0.001$ \\
\hline Chronic kidney disease & $104 / 1543(6.7)$ & $16 / 639(2.5)$ & $88 / 904(9.7)$ & $<0.001$ \\
\hline Cirrhosis & $28 / 1540(1.8)$ & 13/638 (2.0) & $15 / 902(1.7)$ & 0.209 \\
\hline Haematological/oncological cancer & $103 / 1540(6.7)$ & $21 / 640(3.3)$ & $82 / 900(9.1)$ & $<0.001$ \\
\hline HIV & $9 / 1542(0.6)$ & $7 / 639(1.1)$ & 2/903 (0.2) & 0.012 \\
\hline Autoimmune disease & $47 / 913(5.1)$ & $17 / 393(4.3)$ & $30 / 520(5.8)$ & 0.328 \\
\hline Symptoms & & & & \\
\hline Fever & $1159 / 1540(75.3)$ & $533 / 638(83.5)$ & 626/902 (69.4) & $<0.001$ \\
\hline Headache & $133 / 1533(8.7)$ & $92 / 634(14.5)$ & $41 / 899(4.6)$ & $<0.001$ \\
\hline Haemoptysis & $26 / 1532(1.7)$ & $15 / 633(2.3)$ & $11 / 899(1.2)$ & 0.207 \\
\hline Chest pain & $134 / 1534(8.7)$ & $79 / 635(12.4)$ & $55 / 899(6.1)$ & $<0.001$ \\
\hline Muscle pain & 291/1534 (19.0) & $166 / 635(26.1)$ & 125/899 (13.9) & $<0.001$ \\
\hline Abdominal pain & 49/1534 (3.19) & $16 / 635(2.52)$ & $33 / 899$ (3.67) & 0.280 \\
\hline Nausea/vomiting & 178/1532 (11.6) & 88/636 (13.8) & $90 / 896(10.0)$ & 0.040 \\
\hline Diarrhoea & $269 / 1530(17.6)$ & $143 / 636(22.5)$ & $126 / 894(14.1)$ & $<0.001$ \\
\hline Skin rash & $8 / 1531(0.5)$ & $5 / 636(0.8)$ & $3 / 895(0.3)$ & 0.087 \\
\hline Anosmia & $41 / 1153(3.6)$ & $29 / 489(5.9)$ & $12 / 664(1.8)$ & $<0.001$ \\
\hline Complications during admission & & & & \\
\hline Bacterial pneumonia & 43/1362 (3.2) & $13 / 551(2.4)$ & $30 / 811(3.7)$ & 0.320 \\
\hline Sepsis & 28/1372 (2.0) & $16 / 554(2.9)$ & $12 / 818(1.5)$ & 0.054 \\
\hline Respiratory distress syndrome & $195 / 1368(14.2)$ & $74 / 550(13.4)$ & $121 / 818(14.8)$ & 0.557 \\
\hline Pneumothorax & $5 / 1373(0.4)$ & $3 / 556(0.5)$ & $2 / 817(0.2)$ & 0.488 \\
\hline Pleural effusion & $29 / 1367(2.1)$ & $6 / 552(1.1)$ & $23 / 815(2.8)$ & 0.032 \\
\hline Stroke & $11 / 1373(0.8)$ & $4 / 555(0.7)$ & $7 / 818(0.9)$ & 0.669 \\
\hline Disseminated intravascular coagulation & $9 / 1369(0.7)$ & $2 / 554(0.4)$ & $7 / 815(0.9)$ & 0.360 \\
\hline Thrombosis & $55 / 824(6.7)$ & 23/338 (6.8) & $32 / 486(6.6)$ & 0.833 \\
\hline Acute renal failure & $165 / 1373(12.0)$ & $37 / 556(6.6)$ & $128 / 817(15.7)$ & $<0.001$ \\
\hline
\end{tabular}


Table 1 Continued

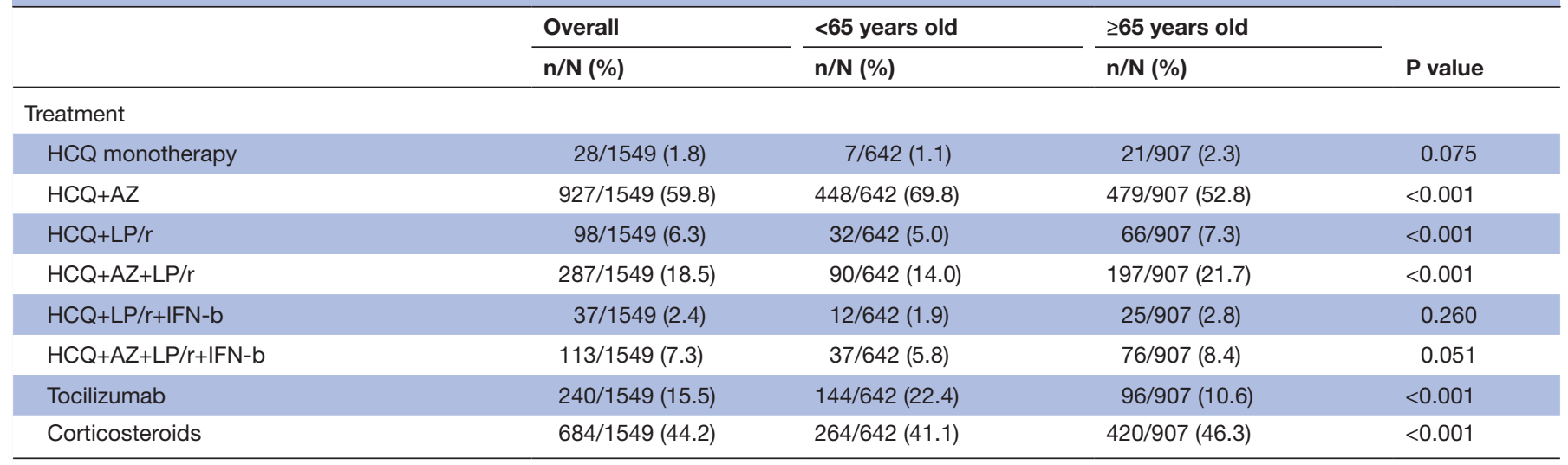

AZ, azithromicine; COPD, chronic obstructive pulmonary disease; HCQ, hydroxicloroquine; IFN-b, interferon-beta; LP/r, lopinavir-ritonavir; OSAS, obstructive sleep apnoea syndrome.

had hypertension, $24.8 \%$ diabetes, $24.3 \%$ cardiovascular disease, $15.7 \%$ obesity, $13.7 \%$ chronic obstructive pulmonary disease (COPD) and $8.5 \%$ obstructive sleep apnoea syndrome (OSAS). HIV infection $(0.6 \%)$ and autoimmune disease $(5.2 \%)$ were rare. Overall, 1221 (78.2\%) patients had at least one underlying comorbidity.

The median lag time between symptoms onset and diagnosis was 7 days (IQR: 4-9) (figure 1). The most common symptoms at presentation were fever $(75.3 \%)$, cough $(65.7 \%)$ and dyspnoea $(58.1 \%)$. Diarrhoea $(17.6 \%)$ and anosmia $(3.6 \%)$ were less common in our case series. Fever, headache, cough, diarrhoea, nausea/vomiting, anosmia, muscle or chest pain were more frequent in younger patients while cognitive deterioration was in older patients (table 1).

The most frequent therapies used for treating COVID-19 were the combination hydroxychloroquine plus azithromycin $(59.9 \%)$ and the combination hydroxychloroquine plus azithromycin plus lopinavir-ritonavir $(18.5 \%)$. Any treatment combination including lopinavir-ritonavir was more frequently used in older patients. Tocilizumab was used in $15.5 \%$ of the patients and corticosteroids in $44.2 \%$ (table 1 ).

The analysis of the complications during admission showed that $14.3 \%$ of patients had acute respiratory distress syndrome with no differences between age groups, $12.0 \%$ had acute kidney failure which was more frequent in older patients $(15.7 \%$ vs $6.7 \%), 6.7 \%$ had a clinical thrombotic event and $0.7 \%$ had disseminated intravascular coagulation (table 1).

Among patients with a complete episode at ILUH, 81 were admitted to ICU: median age 62 (IQR 51-71); $74.1 \%$ men; median length of stay 9 days (IQR 5-19) and $82.7 \%$ of them needed invasive ventilation support. Clinical characteristics are shown in table 2. Among the 575 patients younger than 65 years old with a complete episode at ILUH, risk factors associated to ICU admission in the univariate analysis were: being men, obesity, hypertension, OSAS, high respiratory rate, a low blood oxygen saturation level at admission, a high neutrophil/lymphocyte ratio, an elevated plasma international normalised ratio, lactate dehydrogenase, aspartate transaminase, creatinine and $\mathrm{C}$ reactive protein and the presence of alveolar pulmonary infiltrates in the chest X-ray (table 2). We calculated CFR in ICU patients with a complete episode at ILUH (70 patients): global CFR was $72.9 \%$ (62.8\% in the under 65 group and $88.9 \%$ in the older group).

The overall CFR in our cohort was 21.2\% (296/1393 cases). The median length of stay was 9 days (IQR 6-14). Among the 296 deaths, 48 occurred in the first 48 hours and the rest during hospitalisation. These 48 patients had a higher median age compared with the global cohort $(82.5$ vs 69) and their median lag time from symptom onset until fatality was lower ( 7 days vs 13.5 days, $\mathrm{p}<0.001$ ). As shown in table 3 , patients who died were older and more likely to be men, current smoker/ex-smoker, and had hypertension, cardiovascular disease, COPD, OSAS, diabetes mellitus, neurological disease, chronic kidney disease and neoplasia in the univariate analysis. Also, they received more frequently ventilatory support during hospitalisation and showed more alveolar pulmonary infiltrates in chest X-ray than people who recovered.

In the multivariate analysis, independent factors related to death were: years of age (OR 1.07; 95\% CI: 1.06 to 1.09 ), being men (OR 2.86; $95 \%$ CI: 1.85 to 4.50 ), neurological disease (OR 1.93; 95\% CI: 1.19 to 3.13), chronic kidney disease (OR 2.83; $95 \%$ CI: 1.40 to 5.71 ) and neoplasia (OR 4.29; 95\% CI: 2.40 to 7.67).

Among the 1549 hospitalised patients, 65 were readmitted (4.2\%): $64.6 \%$ were men and $67.7 \%$ were 65 years old or older. CFR during readmissions was $10.8 \%(7 / 65)$.

\section{DISCUSSION}

This study describes the COVID-19 series of a secondary level hospital in Madrid, Spain.

During the outbreak, hospital wards almost doubled their capacity $(702 / 361)$, with the number of patients in ICU quadrupling its capacity (32/8). Beds were brought from other hospitals (antique not working hospitals) to turn single rooms into double rooms and to make surge beds in large waiting room areas, which became ward beds. A cohort system (confirmed cases located together 
Table 2 Clinical, laboratory and diagnosis imaging characteristics of patients with COVID-19 who have been admitted in ICU $<65$-year-old patients $(n=575)$

\begin{tabular}{|c|c|c|c|c|}
\hline & \multirow[b]{2}{*}{ ICU patients cohort $(n=81)$} & \multicolumn{3}{|c|}{$<65$-year-oid patients $(n=5 / 5)$} \\
\hline & & Admitted to ICU (n=50) & $\begin{array}{l}\text { Non-admitted to ICU } \\
(n=525)\end{array}$ & $P$ value \\
\hline $\mathrm{Age}^{*}$ & $62(51-71)(\mathrm{N}=81)$ & $54(48-60)(N=50)$ & $53(45-59)(N=525)$ & 0.625 \\
\hline Migrant† & 25/81 (30.9) & $21 / 50(42.0)$ & $238 / 525(45.3)$ & 0.651 \\
\hline Influenza vaccine 19/20† & 12/42 (28.6) & $5 / 28(17.9)$ & 75/395 (19.0) & 0.883 \\
\hline High blood pressure $†$ & $43 / 81(53.1)$ & $23 / 50(46.0)$ & $147 / 524(28.1)$ & 0.008 \\
\hline Diabetes mellitus $†$ & 23/81 (28.4) & $10 / 50(20.0)$ & $65 / 519(12.5)$ & 0.315 \\
\hline Tobacco smoker/ex-smoker† & 23/76 (30.3) & $13 / 49(26.5)$ & $98 / 450(21.8)$ & 0.447 \\
\hline Obesity† & 23/81 (28.4) & $17 / 50(34.0)$ & $80 / 520(15.4)$ & 0.001 \\
\hline Thromboembolic disease $\dagger$ & $2 / 40(5.0)$ & $2 / 28(7.1)$ & 8/338 (2.4) & 0.136 \\
\hline Neurological disease $†$ & $5 / 80(6.3)$ & $2 / 49(4.1)$ & $31 / 521(6.0)$ & 0.786 \\
\hline Chronic kidney disease $†$ & $5 / 81(6.2)$ & $3 / 50(6.0)$ & 12/522 (2.3) & 0.118 \\
\hline Liver cirrhosis $†$ & $1 / 80(1.3)$ & $1 / 50(2.0)$ & $11 / 522(2.1)$ & 0.117 \\
\hline $\begin{array}{l}\text { Haematological/oncological } \\
\text { cancer† }\end{array}$ & $4 / 81(4.9)$ & $1 / 50(2.0)$ & 19/523 (3.6) & 0.548 \\
\hline HIV $†$ & $0 / 81(0.0)$ & $0 / 50(0.0)$ & $7 / 522(1.3)$ & 0.529 \\
\hline \multicolumn{5}{|l|}{ Clinical and laboratory presentation } \\
\hline Heart rate (beats per minute) ${ }^{\star}$ & $94(83-107)(N=73)$ & $54(48-60)(N=50)$ & $53(45-59)(\mathrm{N}=525)$ & 0.625 \\
\hline $\begin{array}{l}\text { Respiratory rate (breaths per } \\
\text { minute) })^{*}\end{array}$ & $23(18-30)(N=44)$ & $24(18-30)(\mathrm{N}=33)$ & $18(16-20)(\mathrm{N}=222)$ & 0.002 \\
\hline Haemoglobin $(g / L)^{\star}$ & $13.9(11.9-15.0)(\mathrm{N}=81)$ & $14.1(12.1-15.2)(\mathrm{N}=50)$ & $14.1(13.1-15.1)(\mathrm{N}=493)$ & 0.946 \\
\hline Neutrophils (cells count $/ \mu \mathrm{L})^{*}$ & $6300(4500-9300)(\mathrm{N}=81)$ & $7000(4600-8800)(\mathrm{N}=50)$ & $4700(3500-6700)(\mathrm{N}=495)$ & 0.001 \\
\hline Lymphocytes (cells count/ $/ \mathrm{L})^{\star}$ & $900(600-1200)(\mathrm{N}=81)$ & $900(700-1300)(\mathrm{N}=50)$ & $1100(800-1400)(\mathrm{N}=495)$ & 0.252 \\
\hline Neutrophil/lymphocyte ratio* & $6.64(5.0-12.7)(\mathrm{N}=81)$ & $6.69(4.8-12.3)(\mathrm{N}=50)$ & $4.4(2.9-7.1)(\mathrm{N}=495)$ & $<0.001$ \\
\hline Platelets $\left(\times 10^{9} / \mathrm{L}\right)^{*}$ & $209(170-267)(\mathrm{N}=81)$ & $205(172-265)(N=50)$ & $213(171-274)(N=495)$ & 0.777 \\
\hline $\mathrm{INR}^{*}$ & $1.1(1.0-1.2)(\mathrm{N}=81)$ & $1.1(1.0-1.2)(\mathrm{N}=50)$ & $1.1(1.0-1.1)(\mathrm{N}=484)$ & 0.035 \\
\hline D-dimer (mg/L)* & $940(485-2095)(\mathrm{N}=56)$ & $790(470-2350)(\mathrm{N}=35)$ & $640(400-1080)(\mathrm{N}=334)$ & 0.163 \\
\hline $\mathrm{LDH}(\mathrm{U} / \mathrm{L})^{*}$ & $408(279-542)(\mathrm{N}=70)$ & $415(279-605)(\mathrm{N}=43)$ & $271(215-348)(\mathrm{N}=430)$ & $<0.001$ \\
\hline $\operatorname{ALT}(\mathrm{U} / \mathrm{L})^{*}$ & $45(32-67)(\mathrm{N}=80)$ & $50(34-80)(\mathrm{N}=50)$ & $44(30-66)(\mathrm{N}=494)$ & 0.075 \\
\hline AST $(U / L)^{*}$ & $59(40-82)(\mathrm{N}=79)$ & $60(43-85)(\mathrm{N}=50)$ & $40(29-57)(\mathrm{N}=485)$ & $<0.001$ \\
\hline Creatinine $(\mathrm{mg} / \mathrm{dL})^{\star}$ & $1.1(0.9-1.3)(\mathrm{N}=78)$ & $1.1(1.0-1.3)(\mathrm{N}=48)$ & $0.9(0.7-1.1)(\mathrm{N}=480)$ & $<0.001$ \\
\hline C reactive protein $(\mathrm{mg} / \mathrm{L})^{*}$ & $1157(481-2054)(\mathrm{N}=80)$ & $1234(678-2133)(\mathrm{N}=49)$ & $522(174-1152)(N=494)$ & $<0.001$ \\
\hline \multicolumn{5}{|l|}{ Diagnosis imaging } \\
\hline Bilateral pulmonary infiltrates $†$ & $61 / 74(82.4)$ & $40 / 46(87.0)$ & $388 / 476(81.5)$ & 0.359 \\
\hline Interstitial pulmonary infiltrates $†$ & $61 / 81(75.3)$ & $38 / 50(76.0)$ & $360 / 525(68.6)$ & 0.277 \\
\hline Alveolar pulmonary infiltrates $\dagger$ & $51 / 81(63.0)$ & $33 / 50(66.0)$ & $230 / 525(43.8)$ & 0.003 \\
\hline
\end{tabular}




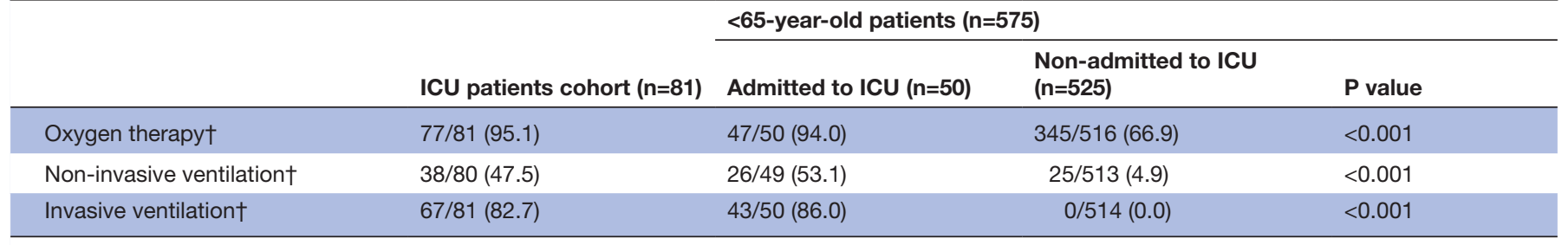

Comparison between patients under 65 years of age admitted to ICU versus non-admitted to ICU.

${ }^{*}$ Continuous variable (median, IQR, N)

†Categorical variables $(\mathrm{n} / \mathrm{N}, \%)$

ALT, alanine aminotransferase; AST, aspartate transaminase; COPD, chronic obstructive pulmonary disease; ICU, intensive care unit; INR, international normalised ratio; LDH, lactate dehydrogenase; OSAS, obstructive sleep apnoea syndrome; SpO2, partial oxygen saturation.

and patients with similar suspect degree too) was followed during the early stages of the epidemic in order to avoid hospital transmission. Some weeks after the beginning of the pandemic, the gym used for patient's rehabilitation was transformed into a semicritical unit where patients discharged from the ICU or patients needing closer monitoring or high-flow oxygen were admitted. The ordinary activity in consultations and elective surgery was cancelled, the paediatric emergencies were referred to other hospitals and all doctors attended patients with COVID-19 exclusively. All physicians and nursing staff were organised into two groups: the COVID-19 assistance group, led by the internal medicine department: they attended patients with COVID-19; and the COVID-19 non-assistance group which gave all the administrative support: requesting laboratory tests, writing clinical reports, informing about clinical evolution to patient's relatives and so on. Regarding critical care beds: our hospital regular capacity comprises eight beds for ICU and six for the surgical critical care. Surge critical care beds were made available in the post-anaesthesia care unit ( 6 beds) and the outpatient surgery post-anaesthesia care unit (12 beds), to a maximum of 32 critical care beds.

Patients' baseline characteristics were similar to the largest published series in Spain, ${ }^{10}$ although our patients were older and with a higher proportion of men compared with other tertiary Spanish hospital series. ${ }^{9}$

We found that younger patients showed a high incidence of fever, cough, headache, muscle pain and diarrhoea, whereas older patients showed a less specific clinical presentation. Other studies did not find differences in clinical presentation related to age. ${ }^{14}$ This information could be crucial for the rapid identification and isolation of the suspected cases at any healthcare level.

Our cohort showed a high incidence of acute kidney failure during hospitalisation similar to other nonSpanish series ${ }^{1516}$ but higher than other Madrid series, ${ }^{9}$ with no association to drug administration. This could be explained for the rapid hydroelectrolytic imbalance in older patients in the context of an acute systemic viral disease. We also found a high incidence of thrombotic events $(6.7 \%)$ comparable with previous reports, ${ }^{17}$ although disseminated intravascular coagulation was rare.
Lopinavir/ritonavir-based treatments were more frequently used in older patients. This finding is due to the use of this drug as standard treatment in our hospital protocol during the first half of the outbreak, when most of the patients were older than 65 years. Tocilizumab, with or without corticosteroids, was used following Spanish Drug Agency recommendations in patients who developed cytokine release storm which is believed to cause acute respiratory distress syndrome, although corticosteroids were also used in other clinical contexts.

During the study, criteria for ICU admission was the need for mechanical ventilation. Due to the number of ICU beds made available for the number of patients admitted to hospital, which doubled the usual hospital capacity, during the study period 22 patients were transferred to other ICUs of Madrid, to make ILUH's ICU beds available for other patients. In the same way, due to the scarce ICU bed capacity, triage of patients had to be done. The selection for ICU admission opportunity was made individually, based on each patient's comorbidities, functional capacity, age (never solely age as a criteria) and depending on the availability of critical care beds at the moment. A local guideline for patient admission on critical care unit was made, based on the consensus document released by the Spanish Society of Intensive and Critical Care and other 17 medical societies. ${ }^{18}$ On the other hand, non-invasive mechanical ventilation or highflow oxygen, managed by pneumologists, was available in the ward for selected patients not admitted to ICU.

Our findings in the ICU analysis in patients under 65 years old were analogous to other studies ${ }^{1619}{ }^{20}$ in terms of clinical characteristics and laboratory values. As described in the New York series ${ }^{16}$ it seems that obesity and OSAS were related factors leading to ICU admission, even more than the presence of a previous pulmonary disease. This could suggest that patients with a baseline ventilatory compromise could entail a higher risk for ICU admission due to alveolar hypoventilation and acute-on-chronic hypercapnic respiratory failure. However, this analysis has some limitations related to scarce availability of ICU resources in our centre and the number of ICU patients who were transferred to other hospitals.

The CFR in our series was $21.2 \%$. It has probably been overestimated due to a significant proportion of patients 
Table 3 Clinical, laboratory and diagnosis imaging characteristics of patients with COVID-19 who died or recovered

\begin{tabular}{|c|c|c|c|}
\hline & Death $(n=296)$ & Recovered $(n=1097)$ & $P$ value \\
\hline Age $^{*}$ & $82(71.5-87)(\mathrm{N}=246)$ & $65(53-78)(N=1097)$ & $<0.001$ \\
\hline Male† & 208/296 (70.3) & $593 / 1097(54.1)$ & $<0.001$ \\
\hline \multicolumn{4}{|l|}{ Clinical background } \\
\hline Influenza vaccine $19 / 20 \dagger$ & $113 / 183(61.7)$ & $342 / 820(41.7)$ & $<0.001$ \\
\hline Cardiovascular disease $\dagger$ & $124 / 296(41.9)$ & 217/1093 (19.8) & $<0.001$ \\
\hline Diabetes mellitus $\dagger$ & 90/295 (30.5) & 260/1090 (23.8) & 0.038 \\
\hline Tobacco smoker/ex-smoker† & $111 / 260(42.7)$ & $236 / 950(23.8)$ & $<0.001$ \\
\hline Obesity† & 42/292 (14.4) & 169/1085 (15.6) & 0.169 \\
\hline COPD† & 67/293 (22.9) & $120 / 1092(11.0)$ & $<0.001$ \\
\hline Asthma† & $17 / 296(5.7)$ & $95 / 1093(8.7)$ & 0.166 \\
\hline Chronic kidney disease $†$ & 40/295 (13.6) & $58 / 1092(5.3)$ & $<0.001$ \\
\hline Liver cirrhosis $†$ & $8 / 292(2.7)$ & $17 / 1093(1.5)$ & 0.352 \\
\hline Haematological/oncological cancer† & 48/293 (16.4) & $50 / 1092(4.6)$ & $<0.001$ \\
\hline $\mathrm{HIV}+$ & $0 / 295(0.0)$ & $8 / 1091(0.7)$ & 0.327 \\
\hline \multicolumn{4}{|l|}{ Clinical and laboratory presentation } \\
\hline Heart rate (beats per minute) ${ }^{\star}$ & $88(78-102)(\mathrm{N}=242)$ & $88(78-100)(\mathrm{N}=881)$ & 0.856 \\
\hline Respiratory rate (breaths per minute) ${ }^{*}$ & $21.5(16-28)(\mathrm{N}=116)$ & $18(16-20.5)(\mathrm{N}=397)$ & $<0.001$ \\
\hline Systolic blood pressure $(\mathrm{mm} \mathrm{Hg})^{*}$ & $130(111-147)(\mathrm{N}=217)$ & $130(117-143)(\mathrm{N}=683)$ & 0.877 \\
\hline $\mathrm{SpO} 2(\%)^{*}$ & $89(82-93)(\mathrm{N}=239)$ & $95(92-97)(\mathrm{N}=945)$ & 0.033 \\
\hline $\mathrm{SpO} 2<90 \% \dagger$ & $121 / 203(59.6)$ & $152 / 945(16.1)$ & $<0.001$ \\
\hline Platelets $\left(\times 10^{9} / \mathrm{L}\right)^{*}$ & $190(142.5-263.5)(\mathrm{N}=292)$ & $209(162-273)(\mathrm{N}=1057)$ & 0.040 \\
\hline $\mathrm{INR}^{*}$ & $1.1(1.0-1.3)(\mathrm{N}=283)$ & $1.1(1.0-1.2)(\mathrm{N}=1026)$ & $<0.001$ \\
\hline D-dimer (mg/L)* & $1060(570-2560)(\mathrm{N}=167)$ & $750(450-1330)(\mathrm{N}=685)$ & $<0.001$ \\
\hline $\mathrm{LDH}(\mathrm{U} / \mathrm{L})^{*}$ & $345(249-479)(\mathrm{N}=235)$ & $259(210-331)(\mathrm{N}=887)$ & $<0.001$ \\
\hline $\operatorname{ALT}(\mathrm{U} / \mathrm{L})^{*}$ & $31(23-47)(\mathrm{N}=287)$ & $36(25-55)(N=1050)$ & $<0.001$ \\
\hline AST $(U / L)^{*}$ & $47(30-67)(N=284)$ & $38(28-55)(N=1035)$ & $<0.001$ \\
\hline Creatinine $(\mathrm{mg} / \mathrm{dL})^{*}$ & $1.2(0.9-1.7)(\mathrm{N}=285)$ & $0.9(0.7-1.2)(\mathrm{N}=1032)$ & $<0.001$ \\
\hline$C$ reactive protein $(\mathrm{mg} / \mathrm{L})^{*}$ & $105.9(36.2-182.4)(\mathrm{N}=291)$ & $53.8(18.3-111.4)$ & $<0.001$ \\
\hline \multicolumn{4}{|l|}{ Diagnosis imaging } \\
\hline Bilateral pulmonary infiltrates $\dagger$ & $218 / 259(84.2)$ & $762 / 960(79.4)$ & 0.084 \\
\hline Interstitial pulmonary infiltrates $†$ & $182 / 296(61.5)$ & $689 / 1097(62.8)$ & 0.677 \\
\hline Alveolar pulmonary infiltrates $\uparrow$ & $153 / 296(51.7)$ & $458 / 1097(41.7)$ & 0.002 \\
\hline \multicolumn{4}{|l|}{ Respiratory supplementation } \\
\hline Oxygen therapy $†$ & 285/292 (97.6) & $458 / 1075$ (76.5) & 0.001 \\
\hline Non-invasive ventilation† & $57 / 289(19.7)$ & $64 / 1072(6.0)$ & $<0.001$ \\
\hline Invasive ventilation & 46/292 (15.7) & $15 / 1075(1.4)$ & $<0.001$ \\
\hline
\end{tabular}

${ }^{*}$ Continuous variable (median, IQR, N)

†Categorical variable $(\mathrm{n} / \mathrm{N}, \%)$

ALT, alanine aminotransferase; AST, aspartate transaminase; COPD, chronic obstructive pulmonary disease; INR, international normalised ratio; LDH, lactate dehydrogenase; OSAS, obstructive sleep apnoea syndrome; SpO2, partial oxygen saturation. 
transferred to other hospitals in the first 48 hours, who had a less severe disease. Some published series showed a lower CFR, ${ }^{21}$ although others reported a similar ${ }^{91016}$ or even higher CFR. ${ }^{1522}$ The differences could be related to demographic factors, different hospital admission criteria, case definition and healthcare system overload level. ${ }^{23}$ It is interesting to note that the CFR found in our study is similar to other Spanish tertiary level hospitals, ${ }^{9}$ despite our sample had a higher proportion of older and male patients and our centre had a lower proportion of conventional hospitalisation and ICU beds availability. The CFR in our ICU was slightly lower than other studies. ${ }^{16}$ Our CFR similar to other hospitals with greater capacity could be related to a better reorganisation of spaces and resources. Some areas of the hospital were reoriented to attend patients with COVID-19 like paediatric or anaesthesia areas. Comparing the patients who died in the first 48 hours (48/296) with the rest of the deceased, the median age was higher and the median days from symptom onset until fatality were lower. This could reflect a steep clinical deterioration in older patients compared with younger patients. Further studies are required to support the evidence of a severe clinical phenotype of SARS-CoV-2 infection characterised by a quick progression of an acute respiratory failure with severe hypoxemia in older patients that leads to fatal outcome.

We found similarities with other series ${ }^{24}$ about variables associated to fatality in the univariate analysis, such as hypertension, cardiovascular disease or pulmonary diseases. Nevertheless, after adjusting by sociodemographic variables and comorbidities at admission, risk factors related to death were age, male gender, neurological disease, chronic kidney disease and cancer. These findings are consistent with other studies that identify male sex and age as important predictors for mortality. ${ }^{25}$ However, this analysis has some limitations because it only focuses on hospitalised patients skewing estimates of the morbi-mortality and risk factors of COVID-19 globally. ${ }^{11}$

The strength of this study lies on the sequential collection of patients (all patients with COVID-19 admitted to hospital were included) and on the complete follow-up of all patients during their entire hospital stay. On the other hand, it also has some limitations. First, its observational and retrospective nature. Second, some variables (ie, anosmia and history of thromboembolic event) have a relatively large number of missing values because they were not registered from the beginning of the study, due to changes in the evidence related to COVID-19 during the progression of the pandemic. Third, there is no follow-up after hospital discharge, so only in-hospital fatality can be estimated.

We are now attending a second outbreak of COVID-19 in Madrid. Compared with the first outbreak, the speed of community transmission is lower, the case detection capacity is higher, there is more knowledge of the disease and the possible treatments and healthcare settings are better prepared. All these factors will probably have a great impact on the analysis if the study were to be repeated now. Future analysis comparing results from first and consecutive waves of COVID-19 pandemic at ILUH would be interesting to make.

\section{CONCLUSION}

This study describes the epidemic progression, clinical characteristics, complications and outcomes of patients with COVID-19 attended in a secondary level hospital in one of the highest COVID-19 incidence neighbourhoods of Madrid, which turned into an entire COVID-19 centre and almost doubled its bed capacity, during the first wave of COVID-19 pandemic in Spain. Fatal outcomes were similar to those reported by hospitals with a higher level of complexity.

\section{Author affiliations}

${ }^{1}$ Preventive Medicine Department, Hospital Universitario Infanta Leonor, Madrid, Spain

${ }^{2}$ Internal Medicine Department, Hospital Universitario Infanta Leonor, Madrid, Spain ${ }^{3}$ Pharmacy Department, Hospital Universitario Infanta Leonor, Madrid, Spain ${ }^{4}$ Emergency Department, Hospital Universitario Infanta Leonor, Madrid, Spain ${ }^{5}$ Anesthesiology Department, Hospital Universitario Infanta Leonor, Madrid, Spain ${ }^{6}$ Intensive Care Department, Hospital Universitario Infanta Leonor, Madrid, Spain ${ }^{7}$ Pediatrics Department, Hospital Universitario Infanta Leonor, Madrid, Spain

\section{Twitter Eva Jiménez @evajgb}

Acknowledgements We are extremely grateful to all the frontline ILUH staff that have worked with great humanity and dedication under enormous pressure. We also thank all the people who have helped us collect the data: Silvia Veleda Sánchez, Laura Zazo Morais, Raquel Ruiz Páez, Pernilla Seidi Tirado Zambrana, María Antonia Cabezas Quintario, María de los Ángeles Martínez Izquierdo, Fernando Manuel Sánchez Aranda, María Sonsoles Sánchez González, Iris Sánchez Egido, Carla Ferrero San Román, Virginia Del Rosario Rodríguez, Juan Gabriel Huertas Peña, Sonia Pérez González, Teresa Collazo Lorduy, Arantzazu Zurrido, Mario Velasco, Laura Serrano, Ester San Segundo, Carlos Domingo, Nuria del Val, Carlota Martín, Laura Salinas and Andrés Merino. We also acknowledge the support of: Paz Arranz García, Rosalía De Dios Álvarez, Juan Rodríguez Moreno, Fernando Cava Valenciano, María Ángeles Rodríguez Martínez, Dulce Ramírez Puerta, Miguel Imaz Díaz, Julio Miguel Vila Blanco and María Carmen Pantoja Zarza.

Collaborators COVID@HUIL Working Group: Blanca Herrero Mendoza (Pediatrics Department, Infanta Leonor University Hospital, Madrid, Spain); Natividad Plazas Andreu (Physical Medicine and Rehabilitation Department, Infanta Leonor University Hospital, Madrid, Spain); Liliana Vázquez Bol (Gynecology and Obstetrics Department, Infanta Leonor University Hospital, Madrid, Spain); Sandra María Gadin López (Anesthesiology Department, Infanta Leonor University Hospital, Madrid, Spain); Álvaro Martínez Alcalá (Gastroenterology Department, Infanta Leonor University Hospital, Madrid, Spain); Sonia Pérez Gonzalez (Urology Department, Infanta Leonor University Hospital, Madrid, Spain); Amalia Martínez de la Gándara (Intensive Care Department, Infanta Leonor University Hospital, Madrid, Spain); Alejandro Zuazua Gonzalez (Otorhinolaryngology Department, Infanta Leonor University Hospital, Madrid, Spain); Javier Montoya Adarraga (Orthopedics Department, Infanta Leonor University Hospital, Madrid, Spain); Miguel Ángel Lara Álvarez (Oncology Department, Infanta Leonor University Hospital, Madrid, Spain); Enrique Calvo Aranda (Rheumatology Department, Infanta Leonor University Hospital, Madrid, Spain); Rosa M Lorente Ramos (Radiology Department, Infanta Leonor University Hospital, Madrid, Spain); María Alcantud (Geriatrics Department, Infanta Leonor University Hospital, Madrid, Spain); Roberto Alcázar Arroyo (Nephrology Department, Infanta Leonor University Hospital, Madrid, Spain); Verónica Suberviola Sánchez-Caballero (Cardiology Department, Infanta Leonor University Hospital, Madrid, Spain); Ariela Candelario Cáceres (Pneumology Department, Infanta Leonor University Hospital, Madrid, Spain); Juan Churruca Sarasqueta (Hematology Department, Infanta Leonor University Hospital, Madrid, Spain); Juan Torres Macho (Internal Medicine Department, Infanta Leonor University Hospital, Madrid, Spain); Ismael Escobar Rodríguez (Pharmacy Department, Infanta Leonor University Hospital, Madrid, Spain); Raquel Ruíz Páez (Preventive Medicine Department, Infanta Leonor University Hospital, Madrid, Spain); Alberto Esquivel López (Neurology Department, Infanta Leonor University Hospital, Madrid, Spain); Pablo de la Cueva Dobao (Dermatology Department, Infanta Leonor University Hospital, Madrid, Spain); Francisco Javier Quintero Gutiérrez del Álamo (Psychiatry and Psychology Department, Infanta Leonor University Hospital, Madrid, Spain); Natalia Blanca López (Allergy Department, Infanta Leonor University Hospital, Madrid, Spain); José García Hinojosa (Ophthalmology Department, Infanta Leonor University Hospital, Madrid, Spain); Cristina Sevillano Collantes (Endocrinology 
Department, Infanta Leonor University Hospital, Madrid, Spain); Alfonso Camacho Aroca (General Surgery Department, Infanta Leonor University Hospital, Madrid, Spain); Tamar Talaván Zañón (Laboratory, Infanta Leonor University Hospital, Madrid, Spain); María Ángeles Sánchez Úriz (Occupational Health Department, Infanta Leonor University Hospital, Madrid, Spain); Carlos Bibiano Guillén (Emergency Department, Infanta Leonor University Hospital, Madrid, Spain); Miguel Ángel López Arenas (Admission Department, Infanta Leonor University Hospital, Madrid, Spain); Margarita Gimeno Arández (Pathology Department, Infanta Leonor University Hospital, Madrid, Spain).

Contributors EJ, MF-V, JV, IF-J, PR and MP-B conceived the study idea. EJ, MF-V, JV, IF-J, PR, MP-B, EAA-A, EI-G and AL contributed to the study design. EJ, MF-V, IF-J, PR, EAA-A, El-G, AL and EG performed the data collection. MF-V and EJ performed the analysis. EJ, MF-V, JV, IF-J, PR, MP-B, EAA-A, EI-G and AL drafted the first version of the manuscript. EJ, MF-V, JV, IF-J, MP-B, PR, EG, EAA-A, EI-G, AL, JT AJT-M, BG-M, GP-L, AA-M and LM critically reviewed the manuscript and approved the final version.

Funding The authors have not declared a specific grant for this research from any funding agency in the public, commercial or not-for-profit sectors.

Competing interests None declared.

Patient consent for publication Not required.

Ethics approval The Institutional Review Board of Infanta Leonor University Hospital approved this study (Code ILUH R 027-20) and due to the retrospective nature, they waived the need for informed consent from patients.

Provenance and peer review Not commissioned; externally peer reviewed.

Data availability statement Data are available upon reasonable request. All data relevant to the study are included in the article or uploaded as supplemental information. Extra data are available by emailing ejgonzalezbuitrago@salud.madrid. org

Supplemental material This content has been supplied by the author(s). It has not been vetted by BMJ Publishing Group Limited (BMJ) and may not have been peer-reviewed. Any opinions or recommendations discussed are solely those of the author(s) and are not endorsed by BMJ. BMJ disclaims all liability and responsibility arising from any reliance placed on the content. Where the content includes any translated material, BMJ does not warrant the accuracy and reliability of the translations (including but not limited to local regulations, clinical guidelines, terminology, drug names and drug dosages), and is not responsible for any error and/or omissions arising from translation and adaptation or otherwise.

Open access This is an open access article distributed in accordance with the Creative Commons Attribution Non Commercial (CC BY-NC 4.0) license, which permits others to distribute, remix, adapt, build upon this work non-commercially, and license their derivative works on different terms, provided the original work is properly cited, appropriate credit is given, any changes made indicated, and the use is non-commercial. See: http://creativecommons.org/licenses/by-nc/4.0/.

\section{ORCID iDs}

Eva Jiménez http://orcid.org/0000-0002-1553-406X

Mario Pérez-Butragueño http://orcid.org/0000-0002-8850-2878

\section{REFERENCES}

1 Coronaviridae Study Group of the International Committee on Taxonomy of Viruses. The species severe acute respiratory syndrome-related coronavirus: classifying 2019-nCoV and naming it SARS-CoV-2. Nat Microbiol 2020;5:536-44.

2 . World Health Organization (WHO). Coronavirus disease (COVID-19) situation Report-129. Available: https://www.who.int/docs/defaultsource/coronaviruse/situation-reports/20200528-covid-19-sitrep129.pdf?sfvrsn=5b154880 2 [Accessed 31 May 2020].

3 World Health Organization (WHO). Novel coronavirus (2019-nCoV) situation report 12. Available: https://www.who.int/docs/defaultsource/coronaviruse/situation-reports/20200201-sitrep-12-ncov.pdf? sfvrsn=273c5d35 [Accessed 02 May 2020].

4 Ministerio de Sanidad,Gobierno de España. Análisis epidemiológico COVID 19. España. Available: https://www.mscbs.gob.es/ profesionales/saludPublica/ccayes/alertasActual/nCov-China/ situacionActual.htm [Accessed 02 May 2020].

5 Ministerio de Sanidad. Centro de Coordinación de Alertas Y Emergencias Sanitarias. Actualización no 197. Enfermedad POR El coronavirus
(COVID-19). Available: https://www.mscbs.gob.es/en/profesionales/ saludPublica/ccayes/alertasActual/nCov/documentos/Actualizacion_ 197_COVID-19.pdf [Accessed 05 Sep 2020].

6 Ministerio de Sanidad. Centro de Coordinación de Alertas Y Emergencias Sanitarias. Actualización no 119. Enfermedad POR E coronavirus (COVID-19), 2020. Available: https://www.mscbs.gob. es/en/profesionales/saludPublica/ccayes/alertasActual/nCov-China/ documentos/Actualizacion_119_COVID-19.pdf [Accessed 6 Jun 2020].

7 Comunidad de Madrid. Hospital Universitario Infanta Leonor. Memoria, 2018. Available: https://www.comunidad.madrid/sites/default/files/doc/ sanidad/memo/hosp-memoria-2018-hinfantaleonor_ok.pdf [Accessed 07 Jun 2020].

8 Comunidad de Madrid,Trasparencia. Covid-19-TIA POR municipios Y distritos de Madrid. Available: https://datos.comunidad.madrid/catalogo/ dataset/covid19_tia_muni_y_distritos [Accessed 01 Jun 2020].

9 Borobia A, Carcas A, Arnalich F, et al. A cohort of patients with COVID-19 in a major teaching hospital in Europe. J Clin Med 2020;9:1733.

10 Casas Rojo JM, Antón Santos JM, Millán Núñez-Cortés J, et al. Clinical characteristics of patients hospitalized with COVID-19 in Spain: results from the SEMI-COVID-19 network. medRxiv, 2020. Available: http://medrxiv.org/content/early/2020/05/26/2020.05.24. 20111971.abstract

11 Prieto-Alhambra D, Ballo E, Coma-Redon E, et al. Hospitalization and 30-day fatality in 121,263 COVID-19 outpatient cases. medRxiv, 2020. Available: http://medrxiv.org/content/early/2020/05/08/2020. 05.04.20090050.abstract

12 Heili-Frades S, Minguez P, Mahillo-Fernandez I, et al. COVID-19 Outcomes in 4712 consecutively confirmed SARS-CoV2 cases in the city of Madrid. medRxiv [Internet], 2020. Available: http:// medrxiv.org/content/early/2020/05/25/2020.05.22.20109850. abstract

13 Harris PA, Taylor R, Thielke R, et al. Research electronic data capture (REDCap)--a metadata-driven methodology and workflow process for providing translational research informatics support. J Biomed Inform 2009;42:377-81.

14 Garg S, Kim L, Whitaker M, et al. MMWR - Hospitalization Rates and Characteristics of Patients Hospitalized with Laboratory-Confirmed Coronavirus Disease 2019 - COVID-NET, 14 States, March 1-30, 2020, 2019. Available: https://www.cdc.gov/coronavirus/2019-ncov/

15 Zhou F, Yu T, Du R, et al. Clinical course and risk factors for mortality of adult inpatients with COVID-19 in Wuhan, China: a retrospective cohort study. Lancet 2020;395:1054-62.

16 Richardson S, Hirsch JS, Narasimhan M, et al. Presenting characteristics, comorbidities, and outcomes among 5700 patients hospitalized with COVID-19 in the new York City area. JAMA 2020;323:jama.2020.6775

17 Lodigiani C, lapichino G, Carenzo L, et al. Venous and arterial thromboembolic complications in COVID-19 patients admitted to an academic hospital in Milan, Italy. Thromb Res 2020;191:9-14.

18 Rubio O, Estella A, Cabre L, et al. [Ethical recommendations for a difficult decision-making in intensive care units due to the exceptional situation of crisis by the COVID-19 pandemia: A rapid review \& consensus of experts]. Med Intensiva 2020;44:439-45.

19 Wang D, Hu B, Hu C, et al. Clinical characteristics of 138 hospitalized patients with 2019 novel coronavirus-infected pneumonia in Wuhan, China. JAMA 2020;323:1061.

20 Grasselli G, Zangrillo A, Zanella A, et al. Baseline characteristics and outcomes of 1591 patients infected with SARS-CoV-2 admitted to ICUs of the Lombardy region, Italy. JAMA 2020;323:1574-8.

21 Gold JAW, Wong KK, Szablewski CM, et al. Characteristics and clinical outcomes of adult patients hospitalized with COVID-19Georgia, March 2020. Morb Mortal Wkly Rpt 2020;69:1-6.

22 Docherty AB, Harrison EM, Green CA, et al. Features of 16,749 hospitalised UK patients with COVID-19 using the ISARIC who clinical characterisation protocol. medRxiv, 2020. Available: http:// medrxiv.org/content/early/2020/04/28/2020.04.23.20076042.abstract

23 Liang WH, Guan WJ, CC L, et al. Clinical characteristics and outcomes of hospitalised patients with COVID-19 treated in Hubei (epicenter) and outside Hubei (non-epicenter): a nationwide analysis of China. Eur Respir J 2020.

24 Chen T, Wu D, Chen H, et al. Clinical characteristics of 113 deceased patients with coronavirus disease 2019: retrospective study. BMJ 2020;368:m1091.

25 Williamson E, Walker AJ, Bhaskaran KJ, et al. OpenSAFELY: factors associated with COVID-19-related Hospital death in the linked electronic health records of 17 million adult NHS patients. medRxiv, 2020. Available: http://medrxiv.org/content/early/2020/05/07/2020. 05.06.20092999.abstract 